\title{
Antifungal activity of schinol and a new biphenyl compound isolated from Schinus terebinthifolius against the pathogenic fungus Paracoccidioides brasiliensis
}

\author{
Susana Johann ${ }^{1,2^{*}}$, Nívea P Sá ${ }^{1}$ Luciana ARS Lima ${ }^{1,3}$, Patricia S Cisalpino ${ }^{2}$, Betania B Cota ${ }^{1}$, Tânia MA Alves ${ }^{1}$, \\ Ezequias P Siqueira', Carlos L Zani ${ }^{1}$
}

\begin{abstract}
Background: The aim of this study was to isolate and identify the antifungal compounds from the extracts of Schinus terebinthifolius (Anacardiaceae) against clinical isolates of the pathogenic fungus Paracoccidioides brasiliensis.

Methods: The hexane and dichlomethane fractions from leaves and stems of S. terebinthifolius were fractionated using several chromatography techniques to afford four compounds.

Results: The compounds isolated from S. terebinthifolius were identified as schinol (1), a new biphenyl compound, namely, 4'-ethyl-4-methyl-2,2',6,6'-tetrahydroxy[1,1'-biphenyl]-4,4'-dicarboxylate (2), quercetin (3), and kaempferol (4). Compounds $\mathbf{1}$ and $\mathbf{2}$ were active against different strains of $P$. brasiliensis, showing a minimal inhibitory concentration value against the isolate $\mathrm{Pb} \mathrm{B} 339$ of $15.6 \mu \mathrm{g} / \mathrm{ml}$. The isolate $\mathrm{Pb} 1578$ was more sensitive to compound 1 with a MIC value of $7.5 \mu \mathrm{g} / \mathrm{ml}$. Schinol presented synergistic effect only when combined with itraconazole. The compounds isolated from S. terebinthifolius were not able to inhibit cell wall synthesis or assembly using the sorbitol assay.

Conclusion: This work reveals for the first time the occurrence of compound $\mathbf{2}$ and discloses activity of compounds $\mathbf{1}$ and $\mathbf{2}$ against several clinical isolates of $P$. brasiliensis. These results justify further studies to clarify the mechanisms of action of these compounds.
\end{abstract}

\section{Background}

Paracoccidioides brasiliensis, a dimorphic fungus occurring in Central and South America, is responsible for paracoccidioidomycosis (PCM), an endemic disease that could affect at least 10 million people in Latin America [1]. However, notification of its occurrence is not compulsory in the countries where it is endemic, hence accurate figures regarding the disease incidence and prevalence are difficult to determine [2]. PCM is a pulmonary infection characterized by cutaneous and/or mucosal lesions that can disseminate to other organs [3]. This disease constitutes an important health problem in

\footnotetext{
* Correspondence: susjohann@yahoo.com.br

'Laboratório de Química de Produtos Naturais, Centro de Pesquisas René Rachou, Belo Horizonte, MG, Brazil

Full list of author information is available at the end of the article
}

Brazil and had also been found in Venezuela, Colombia, Ecuador and Argentina [1].

Two forms of the disease have been described in the literature: the acute (subacute) juvenile form and the chronic adult form; the former runs a faster course and is more severe than the latter [4]. However, in both cases, cell-mediated immune functions are abnormal and, in the absence of specific therapy, mortality is high. Even if improvements are observed in patients after specific treatment, lesions usually remain as sequels [5]. The disease may develop either directly from a primary focus with no latency period or, more commonly, by reactivation of quiescent infections [1].

The drugs most commonly used for treating patients with PCM are sulfonamides, ketoconazole, itraconazole, and amphotericin B. Sulfonamides were the first class of 
drugs available for treating patients with PCM, but long periods of treatment may be required (more than 2 years), with increasing concern about drug toxicity, cost of treatment, and unacceptable rates of noncompliance with therapy $[1,6,7]$. Unfortunately, amphotericin B has been associated with substantial toxicity. Although itraconazole and ketoconazole are effective against $P$. brasiliensis, a long duration of therapy and sometimes a lifelong secondary prophylaxis are required, especially in AIDS patients with high relapse incidence [3].

With the aim of discovering new drug leads that could result in new chemotherapeutic or chemoprophylatic agents to combat $P$. brasiliensis infectitons, our group screened Brazilian medicinal plant's extracts against isolates of P. brasiliensis [8]. Among these plants, Schinus terebinthifolius showed strong activity against clinical isolates of P. brasiliensis. S. terebinthifolius Raddi (Anacardiaceae) is a perennial tree occurring in the Brazilian coast. It is known by a variety of common names, e.g., "aroeiravermelha" and "aroeira pimenteira" [9]. Many biological properties for this medicinal plant were described in the literature: antioxidant and wound-healing [10], antitumoral [9], and antimicrobial activities [11-13,8]. We report herein for first time the investigation of natural products isolated from this plant using in vitro assays with P. brasiliensis.

\section{Methods}

Maintenance of $P$. brasiliensis strains

Five clinical P. brasiliensis strains, Pb01 (ATCC- MYA826), PbB339 (ATCC 32069), Pb18 (Faculty of Medicine, Universidade de São Paulo, São Paulo, Brazil), Pb3 (clinical isolate from chronic PCM, São Paulo, Brazil- MHH Forjaz/TIE Svidzinski), and Pb1578 (clinical isolate PCM, Goiás, Brazil, kindly provided by Dr. Maristela Pereira, Universidade Federal de Goiás) were used in the biological assays. The strains of $P$. brasiliensis were maintained by continuous passages in YPD (yeast, peptone and dextrose) medium at $37^{\circ} \mathrm{C}$. The fungi were used after 7-10 days of growth.

\section{Plant material}

The aerial parts of S. terebinthifolius (germplasm bank number 44) were collected at EPAGRI (Empresa de Pesquisa Agropecuária e Extensão Rural de Santa Catarina), Itajaí, Santa Catarina, Brazil, in January 2004.

\section{Extract preparation}

The dried leaves (400 g) were extracted by maceration in four liter of ethanol $80 \%$ during ten days. After solvent elimination, $36 \mathrm{~g}$ of a hydroalcoholic extract (HAL) was obtained. This extract was then partitioned between water and, successively, with hexane, dichloromethane, and ethyl acetate, resulting in $1.4 \mathrm{~g}$ of an hexane fraction (HEX-L), $5.0 \mathrm{~g}$ of a dichloromethane fraction (DCM-L), and $6.6 \mathrm{~g}$ of the ethyl acetate fraction (EA-L), and $15.2 \mathrm{~g}$ of the aqueous fraction (AQ-L). The plant stems (250 g) were submitted to the same procedure resulting in $1.0 \mathrm{~g}$ (HEX-S), $3.2 \mathrm{~g}$ (DCM-S), $0.8 \mathrm{~g}$ (EA-S), and $4.8 \mathrm{~g}(\mathrm{AQ}-\mathrm{S})$ fractions, respectively $[13,8]$.

\section{Instruments (General procedures)}

Silica gel Merck 60G (70-230 mesh) was used for column chromatography and silica gel pre-coated plates Merck $60 \mathrm{~F}_{254}$ were used for thin-layer chromatography (TLC). The spots on TLC were visualized under UV at 254 and $366 \mathrm{~nm}$ and also after spraying with vanillin$\mathrm{H}_{2} \mathrm{SO}_{4}$ and heating at $120^{\circ} \mathrm{C}$ for $10 \mathrm{~min}$. Plates were sprayed with NP-PEG (polyethylene glycol reagent for visualization of flavonoids. Gel filtration was run on columns filled with Sephadex LH-20. Analytical HPLC (high-performance liquid chromatography) were run on a Shimadzu chromatograph equipped with a LC10AD pump, a dual wavelength detector set to $210 \mathrm{~nm}$ and $240 \mathrm{~nm}$, and using a Shim-pack $\mathrm{C}_{18}$ column $(5 \mu \mathrm{m}$ particle size, $4.6 \times 250 \mathrm{~mm}$ ) at a $1 \mathrm{ml} / \mathrm{min}$ flow rate. Semipreparative HPLC was run on the same equipment described above using a Shim-pack $C_{18}(5 \mu \mathrm{m}$ particle size, $20 \times 250 \mathrm{~mm}$ ) column and $10 \mathrm{ml} / \mathrm{min}$ flow rate. Pro-analysis and HPLC grade solvents were purchased from Vetec (São Paulo, Brazil) and Sigma Chemical Co (St. Louis, USA), respectively. The ESI-MS ${ }^{\mathrm{n}}$ mass spectra were obtained on an ion trap LCQ Advantage (Thermo Electron, San Jose, CA, USA) mass spectrometer operating in the positive and negative ion modes with an electrospray ionization (ESI) source. The samples were injected directly into the ESI source using the equipment micro syringe. The heated capillary temperature was $200^{\circ} \mathrm{C}$, the sheath gas flow rate set to 20 arbitrary units, and spray voltage regulated to $4.5 \mathrm{kV}$. 1D and 2D NMR (nuclear magnetic resonance) spectra were recorded in $\mathrm{CD}_{3} \mathrm{OD}$ and DMSO- $\mathrm{d}_{6}$ on a Bruker Avance DRX $400 \mathrm{MHz}$ spectrometer, using tetrametilsylane as internal standard.

\section{Chromatographic fractionation of the extracts}

HEX-L (1 g) was chromatographed on a column $(46 \times 3$ $\mathrm{cm}$ ) filled with $60 \mathrm{~g}$ of silica gel eluted with mixtures of hexane-methanol of increasing polarity. Seventy-four fractions were collected and tested against $P$. brasiliensis (isolate $\mathrm{Pb} 18)$. The fractions $10-15$ were grouped (26 mg) and fractionated by RP-HPLC on a Shim-pack $\mathrm{C}_{18} 5 \mu \mathrm{m}, 20 \times$ $250 \mathrm{~mm}$ column using a gradient of $\mathrm{MeOH}$-water (90$100 \%$ of $\mathrm{MeOH}$ for $20 \mathrm{~min}$ ) at flow rate $10 \mathrm{ml} \mathrm{min}^{-1}$ and the absorbance of the effluent measured at 210 and $240 \mathrm{~nm}$. This procedure afforded $15.0 \mathrm{mg}$ of compound 1 .

DCM-S (3 g) was injected in a $46 \times 3 \mathrm{~cm}$ column containing $200 \mathrm{~g}$ of silica gel and eluted with a step-gradient 
of hexane-methanol of increasing polarity. The collected fractions (127) were combined according to their TLC profile in 37 groups. All groups were tested against $P$. brasiliensis $(\mathrm{Pb} 18)$ and the majority showed antifungal activity. Group 23 (249 mg) was purified by RP-HPLC in acetonitrile-water gradient from 10 to $50 \%$ in $40 \mathrm{~min}$ and from 50 to $100 \%$ in $10 \mathrm{~min}$, the effluent absorbance was monitored at $220 \mathrm{~nm}$ and $240 \mathrm{~nm}$. This experiment yielded three fractions which were subjected to gel filtration in a $30 \times 2 \mathrm{~cm}$ column filled with Sephadex LH-20 and eluted with $\mathrm{MeOH}$ at a flow of $0.5 \mathrm{ml} / \mathrm{min}$. In this way it was possible to isolate $17.0 \mathrm{mg}$ of compound 2 and $15.0 \mathrm{mg}$ of compound 3 and compound $\mathbf{4}(2.6 \mathrm{mg})$.

\section{Antifungal activity}

\section{Determination of minimal inhibitory concentrations (MIC)}

The bioassay with all isolates of $P$. brasiliensis was performed following CLSI M27- $\mathrm{A}_{2}$ guidelines [14] and modifications suggested by Nakai et al. [15] and Johann et al. [8]. Amphotericin B (Sigma, St Louis, USA) and trimethoprim/sulfamethoxazole (SMT/TMP) (Ducto, Brazil) were included as positive antifungal controls. The concentrations of $25-0.03 \mu \mathrm{g} / \mathrm{ml}$ for amphotericin B and $600-1.17 \mu \mathrm{g} / \mathrm{ml}$ for SMT/TMP were used. Their stock solutions were prepared in DMSO (dimethylsulfoxide) and water, respectively, from which twofold serial dilutions were prepared as described in the CLSI document $\mathrm{M}$ 27- $\mathrm{A}_{2}$ [14].

\section{Minimal fungicidal concentrations (MFC)}

The in vitro minimal fungicidal concentration (MFC) of each compound tested was determined by streaking $10 \mu \mathrm{l}$ from each well that showed complete inhibition (100\% inhibition or a clear well), from the last positive well (growth similar to that of the growth control well), and from the growth control well onto YPD plates. The plates were incubated at $37^{\circ} \mathrm{C}$ for 7 days only. The lowest drug concentration at which no colonies were able to grow was taken as the MFC value [16].

\section{Sorbitol protection assay}

MIC values were determined for the P. brasiliensis isolate $\mathrm{Pb} 18$ using the standard broth microdilution procedure described above. Duplicate plates were prepared: one containing twofold dilutions (from 1000 to $7.8 \mu \mathrm{g}$ / $\mathrm{ml}$ ) of compounds $\mathbf{1}$ and $\mathbf{2}$ and the other containing compounds 1 and 2 plus $0.8 \mathrm{M}$ sorbitol. MICs were evaluated after 7 and 10 days of incubation [17].

\section{Checkerboard microtiter test}

Eight serial twofold dilutions (from 1000 to $7.8 \mu \mathrm{g} / \mathrm{ml}$ ) of compounds 1 and 2 and amphotericin B (from 1 to $0.007 \mu \mathrm{g} / \mathrm{ml}$ ) were prepared with the same solvents used in the MIC test. The checkerboard was prepared in microtiter plate for multiple combinations of two antimicrobial agents. Each row (x axis) in the plate contained the same diluted concentration of the first antimicrobial compound; while the concentration in each subsequent row was half this value. Similarly each column (y axis) in the plate contained the same diluted concentration of the second antimicrobial compound; while the concentration in each subsequent column was half this value. The drug combination in which the growth is completely inhibited was taken as effective MIC for the combination [18].

A 100- $\mu$ l suspension of $\mathrm{Pb} 18$, the same isolate used in the MIC test, was added to each well and cultured for 14 days. Fractional inhibitory concentrations (FICs) were calculated as the MIC of the combination of amphotericin $\mathrm{B}$ and compounds 1 and 2 divided by the MIC of compounds 1 and 2 or AMB amphotericin B alone. The FIC index was calculated by adding both FICs and this was interpreted in the following manner: a synergistic effect when its value is $\leq 0.5$; no interaction when the value falls within the $>0.5$ to 4.0 range; and antagonistic effect when it is $>4.0$. This experiment was also performed to determine the effect of a combination of active compounds with SMT/TMP and itraconazole (Janssen-Cilag) [19-21].

\section{Results}

The hexane (HEX-L) and dichloromethane (DCM-S) fractions of crude extracts from stems and leaves of S. terebinthifolius were selected for chemical fractionation because they exhibited the strongest activities against isolates $\mathrm{Pb} 01, \mathrm{~Pb} 18$, and $\mathrm{PbB} 339$ of P. brasiliensis and had not presented any toxicity to murine macrophages [8]. The activity of crude extracts of steam and leaves was noted at $30 \mu \mathrm{g} / \mathrm{ml}$ for the three isolates de $P$. brasiliensis aforesaid. For fractions HEX-L the activity was noted at $15.2-125 \mu \mathrm{g} / \mathrm{ml}$ for the isolates tested and for DCM-S the activity was at $30 \mu \mathrm{g} / \mathrm{ml}$. However, the fractions EA-S, EA$\mathrm{L}$, aqueous steam and aqueous leaves did not present good activity with MIC values of $125-1000 \mu \mathrm{g} / \mathrm{ml}$ for EA fractions and $625-1000 \mu \mathrm{g} / \mathrm{ml}$ for aqueous fractions against isolates $\mathrm{Pb} 01, \mathrm{~Pb} 18$, and $\mathrm{PbB} 339$ of P. brasiliensis.

After several chromatographic procedures, compound $\mathbf{1}$ was isolated from the HEX-L fraction of $S$. terebinthifolius. Compounds 2, 3, and $\mathbf{4}$ were isolated from the DCM-S fraction. Their spectral data (ESI-MS, NMR, UV) were obtained; analysis and comparison with data from the literature allowed us to identify 1 as schinol; 2 as 4'-ethyl4-methyl-2,2',6,6'-tetrahydroxy[1,1'-biphenyl]-4,4'-dicarboxylate; $\mathbf{3}$ as quercetin; and $\mathbf{4}$ as kaempferol (Additional file 1).

Compounds 1 and 2 (Figure 1) showed antifungal activity at concentrations $\leq 250 \mu \mathrm{g} / \mathrm{ml}$ against five isolates of $P$. brasiliensis (Table 1). Compound 1 displayed activity for the majority of the isolates of $P$. brasiliensis, with MIC values varying from 7.5 to $125 \mu \mathrm{g} / \mathrm{ml}$. The flavonols $\mathbf{3}$ and $\mathbf{4}$ were inactive at the highest concentration tested $(250 \mu \mathrm{g} / \mathrm{ml})$. 
<smiles>C/C(=C/CCC(C)[C@H]1CC[C@]2(C)C3=CCC4C(C)(CC[C@H](O)C4(C)C)C3CC[C@]12C)C(=O)O</smiles>

Compound 1<smiles>CCOC(=O)c1cc(O)c(-c2c(O)cc(C(=O)OC)cc2O)c(O)c1</smiles>

Compound 2
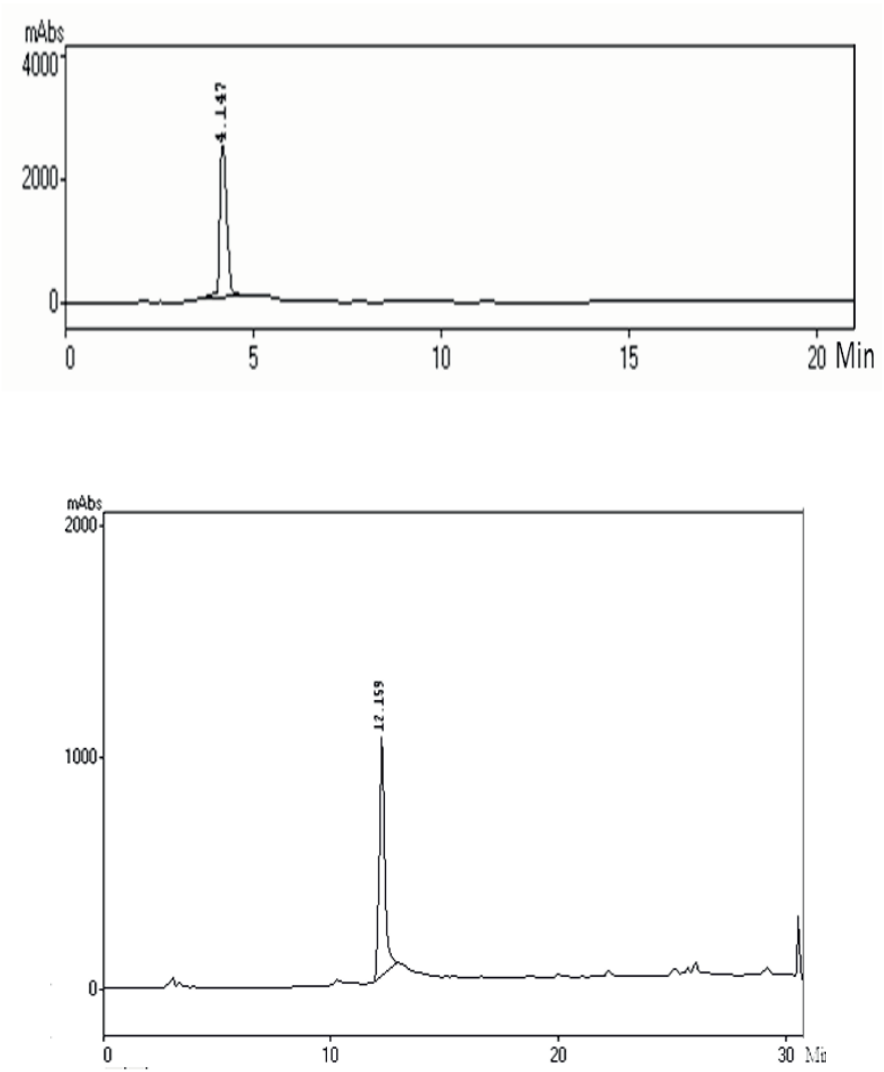

Figure 1 Antifungal compounds and chromatograms against Paracoccidiodes brasiliensis solated from Schinus terebinthifolius. Compound 1: schinol; compound 2: biphenyl 4'-ethyl-4-methyl-2,2',6,6'-tetrahydroxy[1,1'-biphenyl]-4,4'-dicarboxylate.

This is the first time that the antifungal activity of compound $\mathbf{1}$ and $\mathbf{2}$ is described. The Minimal fungicidal activity was identical to CIM for compounds $\mathbf{1}$ and $\mathbf{2}$, showing that these compounds have fungicidal activity against $P$. brasiliensis.

Compounds 1 and 2 were tested on the isolate $\mathrm{Pb} 18$ of $P$. brasiliensis in the presence of sorbitol and showed

Table 1 Minimal inhibitory concentrations (MIC) compounds isolated from Schinus terebinthifolius against different isolates of Paraccocidioides brasiliensis (values in $\mu \mathrm{g} / \mathrm{ml}$ )

\begin{tabular}{llllll}
\hline & Pb18 & Pb01 & Pb3 & PbB339 & Pb1578 \\
\hline Compound 1 & 62.5 & 125 & 31.2 & 15.6 & 7.5 \\
Compound 2 & 250 & 125 & 250 & 15.6 & 250 \\
Compound 3 & $\geq 250$ & $\geq 250$ & $\geq 250$ & $\geq 250$ & $\geq 250$ \\
Compound 4 & $\geq 250$ & $\geq 250$ & $\geq 250$ & $\geq 250$ & $\geq 250$ \\
Amphotericin B* & 0.0062 & 0.12 & 0.015 & 0.0062 & 0.0062 \\
$\begin{array}{l}\text { Trimethoprim- } \\
\text { sulfamethoxazol* }\end{array}$ & 300 & 300 & 300 & 75 & 75 \\
\hline Compond 1: & & & & & \\
\hline
\end{tabular}

Compound 1: schinol; compound 2: 4'-ethyl-4-methyl-2,2',6,6'-tetrahydroxy [1,1'-biphenyl]-4,4'-dicarboxylate; compound 3: quercetin; and compound 4: kaempferol. The concentrations of $25-0.03 \mu \mathrm{g} / \mathrm{ml}$ for used for amphotericin $B$ and $600-1.17 \mu \mathrm{g} / \mathrm{ml}$ for SMT/TMP.
MIC values similar to those of the medium without sorbitol. Table 2 shows the results of combining known antifungal drugs with compounds $\mathbf{1}$ and $\mathbf{2}$. When itraconazole was combined with compound $\mathbf{1}$, the concentration of the former was halved and that of the latter decreased four times, indicating a synergistic effect (fractional inhibiting concentration index $=0.5$ ) between these substances. No synergy could be observed for the other combinations.

\section{Discussion}

In a previous work, our group detected the activity of crude extracts from leaves and stems of $S$. terebinthifolius against clinical isolates of $P$. brasiliensis, Cryptococcus neoformans, Sporothrix schenkii, and five clinical relevant species of Candida [13,8]. The antimicrobial activity of the crude extract from the leaves of $S$. terebinthifolius against Staphylococcus aureus, Bacillus subtilis, Pseudomonas aeruginosa, Escherichia coli, and C. albicans has been reported elsewhere [12].

According to Johann et al. [13] the leaf extract of S. terebinthifolius showed the presence of saponins, flavonoids, triterpenes, steroids, and tannins. Loyd et al. [22] 
Table 2 Synergism activity between compounds 1 and 2 with amphotericin $B$, trimethoprim-sulfamethoxazole and itraconazole against Paracocidioides brasiliensis (isolate Pb18)

\begin{tabular}{ll}
\hline Combination & FIC \\
\hline Compound $\mathbf{2}+$ amphotericin B & $1(\mathrm{I})^{1}$ \\
Compound $\mathbf{2}+$ trimethoprim-sulfamethoxazole & $1.5(\mathrm{I})^{1}$ \\
Compound $\mathbf{2}+$ itraconazole & $1(\mathrm{I})^{1}$ \\
Compound $\mathbf{1}+$ amphotericin B & $1(\mathrm{I})^{1}$ \\
Compound $\mathbf{1}+$ trimethoprim-sulfamethoxazole & $1.5(\mathrm{I})^{1}$ \\
Compound $\mathbf{1}+$ itraconazole & $0.5(\mathrm{~S})^{1}$
\end{tabular}

${ }^{1} S$, synergy; I, no effect; A, antagonism.

Compound 1: schinol, compound 2: 4'-ethyl-4-methyl-2,2',6,6'-tetrahydroxy [1,1'-biphenyl]-4,4'-dicarboxylate.

reported the presence of sesqui- and triterpenes. The tetracyclic triterpene schinol (1) was first isolated by Kaistha and Kier [23]. It was further isolated from other plant species such as Juliana adstringens (Julianiaceae) [24]. We describe here for the first time the isolation and identification of compound 2 (4'-ethyl-4-methyl-2,6,2',6'tetrahydroxy[1,1'-biphenyl]-4,4'-dicarboxylate, for NMR data (Additional file 1). This new biphenyl compound is a positional isomer of 4'-ethyl-4-methyl-2,6,3',5'-tetrahydroxy[1,1'-biphenyl]-4,4'-dicarboxylate, a compound already isolated from fruits of S. terebinthifolius [25]. This was the first report of the isolation of the flavonols quercetin (3) and kaempferol (4) from S. terebinthifolius. However, both compounds have already been described among species of the genus Schinus [26].

When the activity of the compounds isolated in this work is compared to the activity of the extracts and fractions of the S. terebinthifolius [8], it is possible to notice that the activity of the $1(7.5-62.5 \mu \mathrm{g} / \mathrm{ml})$ was better than the original fraction HE-L $(15.2-125 \mu \mathrm{g} / \mathrm{ml})$. These results suggest that 1 could be the main active compound, since the other fractions did not present important activity.

The activity of the original fraction of the compound 2 was $15.6-125 \mu \mathrm{g} / \mathrm{ml}$ and the crude extract (DCM-S) was $30 \mu \mathrm{g} / \mathrm{ml}$, thus, other active compounds could be present and by means of synergism, have greater potency than isolated compounds.

The isolates Pb1578 and PbB339 were more sensitive to compounds $\mathbf{1}$ and 2 , respectively; they were also more susceptible to SMT/TMP when compared with other isolates of $P$. brasiliensis. $\mathrm{Pb} 01$ was the isolate most resistant to compound $1(150 \mu \mathrm{g} / \mathrm{ml})$, while isolates $\mathrm{Pb} 18$ and $\mathrm{Pb} 3$ were more resistant to compound 2 . In the present work we tested fungal isolates of $P$. brasiliensis of 2 distinct cryptic phylogenetic species: S1 (Pb18) and PS2 (Pb03) [27]. $\mathrm{Pb} 01$ and $\mathrm{Pb} 1578$ are known as isolates representative of a new phylogenetic species Pb-01-like [28]. Teixeira et al. [28] recommended the formal description of the "Pb-01-like" cluster as the new species Paracoccidioides lutzii.

In the present work, compound 4 (kaempferol) did not present any antifungal activity. However, glucosylated derivates of kaempferol such as 3-O- $\beta$-D-glycopyranosyl $(1 \rightarrow 2)$-O- $\beta$-D-glucopyranosil $(1 \rightarrow 2)$ - $O$-[ $\alpha$-L-rhamnopyranosyl- $(1 \rightarrow 6)]-\beta-D$ glucopyranoside showed activity against different isolates of Fusarium oxysporum [29]. Yordanov et al. [30] showed that kaempferol is a potential inhibitor of the virulent factors (lipolytic and proteinase activities) responsible for the penetration of $C$. albicans into human cells.

Báidez et al. [31] have shown that quercetin (3) exhibits activity against Phytophthora megasperma and Cylindrocarpon destructans. However, in the present work, we found that this compound did not present any activity against $P$. brasiliensis.

Antifungal activity may be due to interference in the cell wall synthesis or assembly. A distinctive feature of compounds acting on the fungal cell wall is that the antifungal effect can be reversed in a medium containing an osmotic stabilizer such as sorbitol. Compounds $\mathbf{1}$ and $\mathbf{2}$ were tested on the isolate $\mathrm{Pb} 18$ of P. brasiliensis in the presence of sorbitol and showed MIC values similar to those of the medium without sorbitol. This result suggests that these compounds may be exerting their antifungal activity via mechanisms other than the inhibition of the cell wall synthesis or assembly. Thus, new experiments are needed in order to determine the mechanism of action of these compounds against $P$. brasiliensis.

Use of combined antifungal drugs with different active mechanisms could be a promising therapeutic approach. In our study, we could confirm the antifungal of schinol as well as the synergistic effect between schinol and itraconazole in $P$. brasiliensis. The synergistic effect between schinol and itraconazole might be clinically useful and valuable because itraconazole has a long duration of therapy [3].

\section{Conclusion}

In the present work, the aerial parts of S. terebinthifolius furnished two antifungal compounds active on $P$. brasiliensis: schinol (1), and new biphenyl identified as 4'-ethyl-4-methyl-2,2',6,6'-tetrahydroxy[1,1'-biphenyl]4,4'-dicarboxylate (2). These natural products will be further studied to evaluate their toxicity and to elucidate their mechanism of action.

\section{Additional material}

Additional file 1: Compounds isolates Dates of $T L C$, retention time $(t R)$ in HPLC, RMN, UV spectrum and ESI-MS of four compounds isolates. 


\section{Acknowledgements}

Funding: This work was funded by Conselho Nacional de Desenvolvimento Científico Tecnológico (CNPq) and the Coordenação de Aperfeiçoamento de Pessoal de Nível Superior (CAPES). This work was also supported by FIOCRUZ through a PDTIS grant (RPT-10)

\section{Author details}

'Laboratório de Química de Produtos Naturais, Centro de Pesquisas René Rachou, Belo Horizonte, MG, Brazil. 'Departamento de Microbiologia, Instituto de Ciências Biológicas, Universidade Federal de Minas Gerais, Belo Horizonte, MG, Brazil. ${ }^{3}$ Campus Centro-Oeste Dona Lindu, Universidade Federal de São João Del-Rei, Divinópolis, MG, Brazil.

\section{Authors' contributions}

SJ was carried out all experimental work, data acquisition and analysis, literature search and writing the manuscript. NPS was responsible for helpful in assay of antifungal activity. LARSL, BBC, EPS and TMAA involved in characterization of isolate compounds from S. terebinthifolius. PSC and CLZ were responsible for study concept, designing and coordinating the research, supervising the work and revising the manuscript. All authors have read and approved the final manuscript.

\section{Competing interests}

The authors declare that they have no competing interests.

Received: 5 August 2010 Accepted: 12 October 2010

Published: 12 October 2010

\section{References}

1. Brummer E, Castañeda E, Restrepo A: Paracoccidioidomycosis: an update. Clin Microbiol Rev 1993, 6:89-117.

2. Gow N, Nino-Veja : Paracoccidioides brasiliensis - the man-hater. Mycologist 2002, 16:77-78.

3. Lorthay O, Denning DW, Dupont B: Endemic mycoses: a treatment update. J Antimicrob Chemother 1999, 43:321-331.

4. Pereira RM, Bucaretchi F, Barison EM, Hessel G, Tresoldi AT: Paracoccidioidomycosis in children: clinical presentation, follow-up and outcome. Rev Instit Med Trop São Paulo 2004, 46:127-131.

5. Cock AM, Cano LE, Vélez D, Aristizábal BH, Trujillo J, Restrepo A: Fibrotic sequelae in pulmonary paracoccidioidomycosis: histopathological aspects in $B A L B / c$ mice infected with viable and non-viable Paracoccidioides brasiliensis propagules. Rev Inst Med Trop São Paulo 2000, 42:59-66.

6. Paniago AM, Aguiar Jl, Aguiar ES, da Cunha RV, Pereira GR, Londero AT, Wanke B: Paracoccidioidomycosis: a clinical and epidemiological study of 422 cases observed in Mato Grosso do Sul. Rev Soc Bras Med Trop 2003, 36:455-9.

7. Travassos $L R$, Taborda CP, Colombo AL: Treatment options for paracoccidioidomycosis and new strategies investigated. Expert Rev Anti Infect Ther 2008, 6:251-62.

8. Johann S, Cisalpino PS, Watanabe GA, Cota BB, Siqueira EP, Pizzolatti MG, Zani $C L$, Resende MA: Antifungal activity of extracts of some plants used in the Brazilian traditional medicine against the pathogenic fungus Paracoccidioides brasiliensis. Pharmac Biol 2010, 48:388-96.

9. Corrêa PM: Dictionary of useful plants from Brazil and exotic cultivated. Rio de Janeiro: Imprensa Nacional 1978, 4324, (In portuguese).

10. Melo EJM Jr, Raposo MJ, Lisboa Neto JÁ: Medicinal plants in the healing of dry socket in rats: Microbiological and microscopic analysis. Phytomedicine 2002, 9:109-116.

11. Amorim MMR, Santos LC: Treatment of bacterial vaginosis with Schinus terebinthifolius Raddi vaginal gel: a randomised controlled trial. Rev Bras Ginecol Obstet 2003, 25:95-102.

12. Schomourlo G, Mendonça-Filho RR, Alviano CS, Costa SS: Screening of antifungal agents using ethanol precipitation and bioautography of medicinal and food plants. J Ethnopharmacol 2006, 96:563-568.

13. Johann S, Pizzolatti MG, Donnici CL, Resende MA: Antifungal properties of plants used in Brazilian traditional medicine against clinically relevant fungal pathogens. Braz J Microbiol 2007, 38:632-637.

14. Clinical and Laboratory Standards Institut (CLSI): Reference method for broth dilution antifungal susceptibility testing of yeasts, as the document is M27-A2, Wayne, PA. USA. 2002.
15. Nakai $T$, Uno J, keda $F$, Jauregui $A$ : In vitro antifungal activity of micafungin (FK463) against dimorphic fungi: comparison of yeast-like and mycelial forms. Antimicrob Agents Chemother 2003, 47:1376-1381.

16. Espinel-Ingroff A, Boyle K, Sheehan DJ: In vitro antifungal activities of voriconazole and reference agents as determined by NCCLS methods: Review of the literature. Mycopathologia 2001, 150:101-115.

17. Escalante A, Gattuso M, Pérez P, Zacchino S: Evidence for the mechanism of action of the antifungal phytolaccoside B isolated from Phytolacca tetramera Hauman. J Nat Prod 2008, 71:1720-1725.

18. Hemaiswarya S, Kruthiventi A, Doble M: Synergism between natural products and antibiotics against infectious diseases. Phytomedicine 2008 15:639-652.

19. White RL, Burgess DS, Mandururu M, Bosso JA: Comparison of three different in vitro methods of detecting synergy: time kill, checkboard, and E-test. Antimicrob Agents Chemother 1996, 40:1914-8.

20. Pyun MS, Shin S: Antifungal effects of the volatile oils from Allium plants against Trichophyton species and synergism of the oil with ketoconazole. Phytomedicine 2004, 13:394-400.

21. Odds FC: Synergy, antagonism, and what the chequerboard puts between them. J Antimicrob Chemother 2003, 52:1

22. Loyd HA, Taysir MJ, Evans L Morton JF: Terpenes of Schinus terebinthifolius. Phytochemistry 1977, 16:1301-1302.

23. Kaistha FK, Kier LE: Structural Studies on the triterpenes of Schinus terebinthifolius. J Pharm Sci 1962, 51:1136.

24. Makino M, Motegi T, Fujimoto Y: Tirucallane-type triterpenes from Juliana adstringens. Phytochemistry 2004, 65:891-896.

25. Kassem MES, El- Desoky SK, Sharaf M: Biphenyl esters and bioflavonoids from fruits of Schinus terebinthifolius. Chem Nat Comp 2004, 40:447-450.

26. Erazo S, Delporte C, Negrete R, Garcia R, Zaldivar M, Iturra G, Caballero E, López JL, Backhouse N: Constituents and biological activities of Schinus polygamus. J Ethnopharmacol 2006, 107:395-400.

27. Matute DR, McEwen JG, Puccia R, Montes BA, San-Blas G, Bagagli E. Rauscher JT, Restrepo A, Morais F, Nino-Veja G, Taylor JW: Cryptic speciation and recombination in the fungus Paracoccidioides brasiliensis as revealed by gene genealogies. Mol Biol Evol 2006, 23:65-73.

28. Teixeira MM, Theodoro RC, de Carvalho MJ Fernandes L, Paes HC, Hahn RC, Mendoza L, Bagagli E, San-Blas G, Felipe MS: Phylogenetic analysis reveals a high level of speciation in the Paracoccidioides genus. Mol Phylogenet Evol 2009, 52:273-83.

29. Galeotti F, Barile E, Curir P, Dolci M, Lanzotti V: Flavonoids from carnation (Dianthus caryophyllus) and their antifungal activity. Phytochem Lett 2008, 1:44-48.

30. Yordanov M, Dimitrova P, Patkar S Saso L, Ivanovska N: Inhibition of Candida albicans extracellular enzyme activity by selected natural substances and their application in Candida infection. Can J Microbiol 2008, 54:435-440.

31. Báidez AG, Gómez P, Del Río JÁ, Ortunõ A: Antifungal capacity of major phenolic compounds of Olea europaea L. against Phytophthora megasperma Drechsler and Cylindrocarpon destructans (Zinssm.) Scholten. Physiol Mol Plant Pathol 2006, 69:224-229.

doi:10.1186/1476-0711-9-30

Cite this article as: Johann et al:: Antifungal activity of schinol and a new biphenyl compound isolated from Schinus terebinthifolius against the pathogenic fungus Paracoccidioides brasiliensis. Annals of Clinical Microbiology and Antimicrobials 2010 9:30. 